\title{
Getting to the root of it: How do faculty address professional boundaries, role expansion, and intra-professional collaboration?
}

\author{
Jacqueline Limoges, Kim Jagos, Sara Lankshear, Sandy Madorin, Deb Witmer \\ Faculty of Health, Wellness and Science, Georgian College, Barrie Campus, Canada
}

Received: March 12, 2018

DOI: $10.5430 /$ jnep.v8n9p113

\author{
Accepted: April 24, 2018 \\ Online Published: May 2, 2018 \\ URL: https://doi.org/10.5430/jnep.v8n9p113
}

\begin{abstract}
Background: Little research exists to guide nursing faculty to respond to the most recent entry-to-practice education changes and subsequent practice and knowledge expansion for nurses. The purpose of this study was to explore the experiences of faculty as they teach about professional boundaries and role clarity to college and university nursing students and how this teaching is connected to in intra-professional collaboration.

Methods: This qualitative research study used a critical feminist sociology to analyze interviews and relevant documents. Twenty-five nursing faculty from an Ontario, Canada school were interviewed.

Results: Through our analysis we detected two main findings. The first was the activation of hierarchies positioning the university program with more status and legitimacy than the college program, and how this established power relations and impeded nursing education for role clarity. The second was the struggle to articulate the actual differences between the roles and contributions of the Registered Practical Nurse (RPN) and the Registered Nurse (RN) and how this struggle impeded education for effective collaboration and role clarity.

Conclusions: Supporting faculty to recognize the distinct and overlapping contributions of each type of nurse can support educational reform that promotes competencies in collaborative care.
\end{abstract}

Key Words: Nursing, Nursing education, Intra-professional collaboration, Nursing faculty, Nursing professionalization

\section{INTRODUCTION}

Meeting students' learning needs so that they are prepared for nursing practice, while at the same time addressing the ongoing professionalization of nursing and the evolving health care system present many challenges for nursing faculty. Compounding these challenges are the competing and oppositional discourses that circulate around nursing - such as the increased demands for collaborative care without strategies to address hierarchies ${ }^{[1-3]}$ boundary demarcation that happens when one profession's role encroaches on what was traditionally the sole realm of another, ${ }^{[4]}$ and staffing models that are often motivated by economics. Faculty require complex understanding of these discourses to address knowledge expansion, overlapping and distinct differences between the Registered Nurse (RN) and Registered Practical Nurse (RPN), and at the same time support nursing professionalization and intra-professional collaboration. Critical theorizing to recognize and address the power relations existing between

\footnotetext{
*Correspondence: Jacqueline Limoges; Email: Jacqueline.Limoges@GeorgianCollege.ca; Address: Faculty of Health, Wellness and Science, Georgian College, Barrie Campus, Canada.
} 
nursing designations is needed to assist faculty to navigate this complex terrain. As this study was conducted in Ontario, Canada, we use the term RPN for the Registered Practical Nurse in this paper. However, in most other provinces in Canada, the term LPN (Licensed Practical Nurse) is used for this same designation of nurse and the term RPN should not be confused with the Registered Psychiatric Nurse.

The aim of this study was to explore the following research questions: What are the experiences of faculty and what discourses do they activate when they teach about professional boundaries and role clarity to both college and university nursing students? and How are faculty connected to the role confusion, boundary work and the collaborative practice of nurses? For this study, we use Smith's ${ }^{[5]}$ definition of discourse that refers to:

A field of relations that includes not only texts and their intertextual conversations, but the activities of people in actual site who produce them and use them and take up the conceptual frames they circulate. This notion of discourse never loses the presence of the subject who activates the text in any local moment of its use. (p. 44)

This definition recognizes faculty as participants in the activation of knowledge that mediates social processes to generate real consequences for the professionalization of nursing.

\section{BACKGROUND}

Significant changes to the educational requirements for entryto-practice for both RNs and RPNs occurred in Ontario, Canada in the mid 2000's (and in other Canadian provinces as well). These changes occurred within already established hierarchies between community colleges and universities, which influenced nursing education. Nursing education is even cited as an example of the contested territory between community colleges and universities. ${ }^{[6]}$ Specifically, community college courses are often considered lower on the knowledge hierarchy due to less abstract or theoretical content, and community college students are considered less academic as admission requirements are lower than university students. ${ }^{[6,7]}$ Community colleges, however, would contest this characterization stating that courses are qualitatively different and cannot be ranked on a common hierarchical scale. None the less, these different views of the two sectors perpetuate power relations by reinforcing the view that one type of education is of higher status and legitimacy ${ }^{[6]}$ and nursing students connect the division within nursing to this hierarchy. ${ }^{[8]}$
The history of nursing education helps to contextualize the current challenge (problematic) related to role clarity and boundary demarcation between RPNs and RNs. In different eras prior to 2004, RNs could gain access to registration (license) from three different education streams: either a two year or a three-year community college diploma, or a four-year baccalaureate in nursing degree. Entry to practice for RPNs could come from an 18-month community college certificate program or a two year community college diploma. Despite these varied education preparations, the distinctions between RN and RPN scopes of practice, the skills each could perform and the places where nurses could work were reasonably clear prior to 2004. However, with the increased credentials requirement for entry to practice to a community college diploma for the RPNs and a $\mathrm{BScN}$ for the RNs in 2004 , role clarity and workplace issues were magnified.

The focus of a knowledge-based curriculum as opposed to a skills-based curriculum for both the RN and the RPN resulted in further blurring. The added education augmented the knowledge base of the RPN graduate and this supported expanding the scope of practice, the skills the RPN could practice, and thus the places where RPNs could work. Coinciding with the credential change were fiscal conditions that prompted nursing and hospital management to optimize the RPN role so that they could take full advantage of the knowledge, skill, and judgment of the RPN whose hourly wage is less than that of the RN. No longer were clinical settings such as pediatrics, obstetrics, and urgent care clinics within emergency departments the sole enclave of the RN. The skills and practice settings that had once been used to define and demarcate RN practice became blurred by the overlap between the RN and the RPN scope of practice. Furthermore, much attention was placed on optimizing the RPN role in the work setting and revising curriculum at school so that they could practice to their full scope of practice. For instance, strategies were put in place to support RPNs to expand medication administration, change complex dressings, complete head to toe assessments and so on. However, there were limited concurrent strategies to support the application of the knowledge gained through baccalaureate education or to optimize the RN role. Concerted efforts to expand and advance $\mathrm{RN}$ practice in areas such as care coordination, safe transitions, patient education and knowledge utilization were scant and resulted in the underutilization of the RN. ${ }^{[9]}$ As such, advancements to the RN role to optimize the use of the $\mathrm{BScN}$ credential have not fully manifested, thus creating challenges in the work setting. To confuse matters even more, there are RPNs and RNs with different education preparations working side by side and as such, there is confusion, lack clarity, and division as they attempt to demarcate their 
roles and contributions to patient care and the health system.

Despite the significance of these changes to nursing education and clinical practice, there is little published research describing the impact of these changes on nursing faculty or how they have adapted nursing curricula in light of these changes. ${ }^{[10]}$ The research related to health-outcomes-by-careprovider ${ }^{[11]}$ has also not been updated since these credential changes, compounding the challenges for faculty in teaching about effective collaboration and consultation strategies between nursing designations. Given the impact these changes have had on nurses' working conditions, overlap in scope of practice, expansion of the RPN role, and the emphasis on collaborative practice, scholarly literature is needed to guide nursing faculty to address the entry-to-practice knowledge requirements to ensure safe, effective intra-professional collaborative care.

\subsection{Influences of professionalizing strategies on nursing education}

For decades, strategies such as creating a distinct body of knowledge, credentialism (requiring a higher level of education), boundary work, professional demarcation, and closure strategies were taken up by nurses in attempts to professionalize. ${ }^{[12,13]}$ These same processes continue today in an attempt to differentiate the RN and RPN roles. To assist in understanding the challenges with professional demarcation currently unfolding between RPNs and RNs, and within nursing education, the professionalizing literature and the history of nursing are now reviewed to conceptualize and provide further background to this research.

The emphasis on professional traits such as a distinct body of knowledge, university education, autonomy, altruism, service, and ethical frameworks were historically used to justify the provision of a high status and increased salaries for those in elite groups such as medicine and law. ${ }^{[14-19]}$ Nurse leaders acknowledged and embraced these traits, recognizing that the educational preparation of nurses was central to workforce issues. ${ }^{[12,13,20]}$ We posit that the increase in credential requirements through the four-year $\mathrm{BScN}$ for the $\mathrm{RN}$ and the two year community college nursing diploma for the RPN are examples of professionalizing tactics aimed at situating nurses as equals within the health care team, and to ensure nurses could meet ever changing patient care needs. The adherence to traits as a professionalizing framework, though, is not sufficient to understand the current context and social processes in which RNs and RPNs are grappling with boundaries and claims of expertise in their practice.

Witz ${ }^{[21]}$ offered a gendered view of closure and professional Published by Sciedu Press project theory that extends the analysis of the professionalizing strategies described above. She explained the process of professionalization (within capitalism and patriarchy) as one that uses exclusionary, demarcationary, inclusionary, and dual closure strategies. Dual closure establishes autonomy for members of the profession, while at the same time limits access to the profession. In nursing, dual closure strategies are evident when we consider the inclusionary practices related to who has legal authority to the title nurse and the call for teamwork and intra-professional collaboration within the family of nursing. Exclusionary practices such as credentialing (college diploma vs degree), creating monopolies by attempting to limit places where RPNs can work, pay structures (where the RN makes more money than the RPN), and hierarchical talk related to skills vs theory are also examples of closure tactics. ${ }^{[8,22]}$ What remains under theorized, though, are the social processes used by nursing faculty to demarcate professional boundaries or how they address overlapping and distinct knowledge between nursing designations, role clarity, and intra-professional collaboration.

\subsection{Intra-professional collaboration}

There is an emerging body of literature pointing to the structures that challenge intra-professional collaboration. For instance, a two-year study explored the influences of education on nursing students in community college and university programs, and revealed how siloed nursing education (in which college and university nursing students are kept apart during their program of study) created unnecessary boundaries and power relations that divided, rather than supported, collaborative practice and perpetuated myths and misconceptions about each designation of nurse. ${ }^{[8,22]}$ This research also showed how BScN education perpetuates a hierarchy where $\mathrm{BScN}$ students are socialized to believe that their degree and theoretical knowledge lead to higher status, and the college diploma students are socialized by faculty and practicing nurses to think that their skill and direct patient contact makes them more relevant. ${ }^{[8]}$ Research with practicing nurses revealed that after graduation RNs and RPNs carry the challenges created during school into the workplace including a lack of awareness of each other's roles. Furthermore, those in leadership positions were not aware of the differences between designations, and that these patterns impeded collaborative nursing practice. ${ }^{[23]}$

The surge of evidence and recommendations regarding collaborative patient-focused care as necessary for effective and safe patient care, highlights the importance of this topic for faculty and is driving education programs to include this in curricula. ${ }^{[24-27]}$ The benefits to collaborative practice have been cited as lower patient mortality rates, reduction in errors 
of omission, higher quality of patient care, improved patient safety, and enhanced job satisfaction. ${ }^{[28-30]}$ Collaboration has also been cited as an ethical imperative as it can promote good and limit harm. ${ }^{[31,32]}$

While in school, students learn through observation of other nurses and from interactions with faculty, peers, and nurses in practice. Given the complex processes described above, it is imperative that nursing education address actual boundaries and overlap, rather than ideological constructions of differences between designations in nursing. Tracing the roots of these processes, some of which are linked to faculty practices, can lead to dismantling power relations within higher education that eventually impact practice. Specific knowledge is still needed to establish the fundamental capacities that create effective, collaborative, and patient centered intra-professional working relationships. ${ }^{[8,22,33-35]}$ If faculty are to guide students through this learning process, it is imperative that faculty understand the discourses that influence their teaching practices and course content. ${ }^{[7]}$ Addressing the social processes activated by faculty that are linked to the confusion and tension between nurses could strengthen nursing education and intra-professional collaboration.

\section{METHODS}

This qualitative research uses ideas from Dorothy Smith's critical feminist sociology $(2005 ; 2006)$ to structure the methods and analysis. Nursing faculty from community college diploma and university degree programs at a large community college in Ontario, Canada were invited to participate in this research. This community college offers a BScN degree (in collaboration with a local university), and a PN diploma programs. The BScN and PN students are co-located on the same campus, and many faculty teach in both programs. Prior to data collection, Research Ethics Board approval was obtained for this study and the research methods conformed to standard practices for the ethical conduct of research involving people.

\subsection{Sample}

The sample for this study consisted of 25 nursing faculty from one Ontario school. Thirteen faculty taught exclusively in the community college diploma program and four taught exclusively in the university degree program. Six participants taught in both the degree and diploma programs and two preferred not to say. The average age of the participants was 51 years. The majority held a Master's degree, all had a $\mathrm{BScN}$ and had been nursing for over 25 years with teaching experience ranging from 5 to 28 years.

116

\subsection{Data collection and analysis}

Faculty were invited to participate in a one-to-one interview about their experiences and thoughts related to how nursing education is involved in the socialization, professional boundary work, and role clarity between RNs and RPNs and how education can support collaborative practice. The one-to-one interviews were conducted by members of the research team, recorded, and then transcribed verbatim. Discourse and textual analysis were conducted using methods informed by Dorothy Smith. ${ }^{[5,36,37]}$

The data for this study included the transcribed interviews from faculty participants and related resources such as documents from the provincial nursing regulatory body (College of Nurses of Ontario) and scholarly literature. Smith's ${ }^{[36]}$ methods involve including documents that guide or direct practice (such as the standards of practice that all nurses must follow or the evidence based literature that informs practice) in the analysis, as these can "bring into view the intersection of the institutions organizing and regulating society with their gender subtext and their basis in a gender division of labour" (p. 3). Smith suggests that it is important to examine events that occurred prior to the situation under investigation, including what she terms extra-local discourses, and the activation of texts at the micro-sociological level to analyze power relations and explore "how things work" (Smith, 1987). Considerations, such as the history of nursing professionalization mentioned previously, are examples of discourses that were included in the analysis of the data.

Data analysis was initially conducted independently where each member of the research team read and considered the data sources to identify patterns and social process. The relationships between what the participants were saying and how these experiences related to the regulatory documents (i.e., professional standards that delineate scopes of practices for RNs and RPNs), the scholarly literature, and other documents that organize nursing education were considered. After individual analysis, the research team continued that analysis as a team, using investigator triangulation in the collection, analysis, and interpretation of the data to enhance the credibility of the findings. The research team continued this process until consensus on the discourses and social processes was achieved.

\section{RESUlts}

Two main findings were detected in the data. The first was the activation of hierarchies positioning the university program with more status and legitimacy than the community college program, and how this established power relations and impeded nursing education for role clarity. The second was the struggle to articulate the actual differences between 
the roles and contributions of the RPN and RN and how this impeded education for effective collaboration and role clarity.

\subsection{Hierarchy and boundaries}

Faculty are acutely aware of how hierarchies related to colleges and universities and credentials demarcate the boundaries between the RN and the RPN. Given that the two nursing programs are co-located in the same building, these hierarchies feature prominently in faculty experiences. The college vs university hierarchies influence their employment preferences and sense of worth as a faculty member. The college vs university hierarchy was expressed and experienced by the faculty participants and reveals the perceived privileged status of the $\mathrm{BScN}$ prepared nurse. Statements such as the following provide insights into this social process:

I've heard faculty say: well, I wouldn't teach in the PN [college] program or I'm not going to teach or step down into that program or I'm an $\mathrm{RN}$, I'm going to teach in the $\mathrm{BScN}$ program. It's almost a case of some people thinking that if you teach in the PN program you do not feel as worthy, educated, articulate, [or] knowledgeable as those that teach in the $\mathrm{BScN}$ (A8), or

I felt bad when I was not teaching in the $\mathrm{BScN}$ program, I felt inferior, I felt like I had been demoted. That is how I felt... because of the prestige. An RPN is not enough... I feel proud to teach in the $\mathrm{BScN}$ program no matter where. Because it is the degree program. It is a cultural thing (A4).

These quotes show how the status that is attached to the degree credential and the hierarchies between college and university are personally experienced.

Faculty were aware that these hierarchies likely spilled over to the students in subtle and not so subtle ways, furthering the division between college and university programs and possibly marginalizing college faculty and students to a 'lesser than' position when hierarchies are left unaddressed. As one faculty member stated, "I've been to faculty meetings where there has been a significant amount of insensitivity towards the role of the practical nurse" (B3). The pervasive yet covert hierarchy is also evident in this quote: "It's intrinsic. It's very hidden...we try to build the PN students up by saying that they are a very valuable member of the profession. But at the same time faculty say... oh, you're just teaching in the PN program or I' $m$ in the BScN. It's very very underhanded and very very subtle." (A2). All participants in the study agreed that the hierarchy is entrenched and problematic.

\section{Ongoing use of siloed education perpetuates boundaries}

The maintenance of silos in nursing education is detected as a power relation and strategy that isolates degree and college nursing students from each other to maintain exclusivity, boundaries, and monopoly claims on certain knowledge forms. This quote exemplifies this process: "I think we create boundaries right from the very beginning because of the way we silo the education and we never truly get them (PN community college diploma and $\mathrm{BScN}$ degree students) together" (B4). Faculty wondered if students are kept apart to perpetuate classist ideas and hierarchical structures and to guard the mystique of ideologies such as critical thinking, clinical reasoning, and so forth. Faculty also suspect that the historical and ongoing siloed education of college and university students is generating lasting consequences for nursing practice. The following quotes typify the faculty views of the consequences of the silos: "So here's a patient, do you give the patient to the RN or the RPN? [Nurses] need to work collaboratively... but they have no skills to do it because we haven't talked about it; because we don't even know how to talk about it" (B8). Another participant added further insights to help understand this process:

I think when you're put in separate camps you have separate activities. And that's how resentment grows, then it builds up and builds up, and then blows. And then what happens?... it's brought out into the workforce. We don't understand the other's role. $(\mathrm{C} 1)$

The siloed education can lead faculty to make assumptions about who is capable of what types of nursing practice, which also perpetuates boundaries. The following quote shows the uneasiness in faculty knowledge and understanding about the different designations in nursing:

RNs [students] are moving to in-depth science [and] knowledge. I see that as the big difference... again I'm not sure how or what they teach in the PN program, but I see what the RN program is, and it [focuses] more on how to learn - I think. Possibly their range of subjects and the things that they do [makes a difference] but then I don't know what the RPN's do (A7).

Paradoxes and ironies stemming from the silos were also identified during the interviews. For instance, while many faculty stated that they could not see the difference between the two designations of nurse and struggled to see how they should be educated differently, they also struggled with suggestions that less capable students in the $\mathrm{BScN}$ program 
could be moved to the PN college diploma program. For instance,

I think the fact that there is overlap muddies the waters as to who really does what and what not. I still find there is very much hierarchical thinking. .. what drives me crazy in our $\mathrm{BScN}$ program is that if we have a student who fails, they are recommended to go into the PN program. I think that is creating a "less than" and "greater than" mentality, and has students referring to it as "dropping down"... I think that we do need to clarify what roles are that each of the nurses do. (A6)

The social processes involved in suggesting that a less capable student 'move-down' to the college diploma program illustrates the hierarchy and mis-understanding between the two nursing designations and the two education programs. Faculty could see how some joint education between programs could support mutual learning and intra-professional collaboration. Faculty suggested that joint education would support students in understanding each other's role and how to optimize knowledge overlap and the distinct contribution to patient care made by each designation. This understanding is revealed in the following quote: "What we really need is a course called intra-professional collaboration with the requirement that students from both programs work together for the whole semester" (B3).

\subsection{Role confusion}

Delivering education about collaborative practice was problematic for faculty who are unsure of the actual differences between the two designations. The overlap in scope of practice, role expansion, and changing roles create confusion for faculty, making articulation and explication of the two designations difficult. Statements such as "the RPN role has changed so fast I don't think we've had time to figure it out" (B2), or "I am having a hard time differentiating between the two and I often wonder if I am applying what I know as a RN to the RPN in clinical because I have certain expectations of how to be as a nurse" (B1). This same participant added later in the interview: "I fully acknowledge that the roles are very blurred... I still struggle to explain the differences between the two". This was a common sentiment of the participants in this study and reveals the lack of clarity they wrestle with. Struggles to articulate differences between the two designations are part of their lived experience of teaching nursing.

These struggles create tension and disjunctures for the faculty which can be seen through statements such as: 118
If I were to go and teach a course for example, to a group of PN students, I would struggle to think how I would teach that differently because they still have to do very similar things [as nurses]. I mean if an RPN has a patient assignment and that patient's condition deteriorates they have to be able to recognize that, they have to be able to recognize what that patient's condition is about and what their scope of practice is. So that involves knowledge and critical thinking. So, I would hope that I wouldn't teach differently. (A6)

Or when A3 stated:

What is the difference and what differentiates us? I don't know the answer. The default position is to mumble depth and breadth - critical thinking, depth and breadth. Now leadership is a good one in that in the $\mathrm{BScN}$ program there is a distinct course on leadership... those are the ones that you fall back on, leadership, depth, breadth, critical thinking.

The fact that most, if not all faculty in the PN college diploma program are RNs perpetuated confusion and role ambiguity as PN college diploma faculty speculated they were educating PN students from an RN point of reference.

The confusion within the faculty around the differences between the two designations of nurse was widespread within the sample. It took courage to acknowledge this lack of clarity, but once this occurred, an opportunity was created where ideological thinking could be challenged and clarity could be sought. Faculty acknowledged that they must develop a clearer sense of what each designation of nurse contributes so that this can be clearly communicated to students. Faculty stated that this understanding could help nursing students reconcile the overlap and distinct differences which would undoubtedly strengthen intra-professional collaboration.

\section{Discussion}

The hegemonic positions related to RNs and RPNs require extra scrutiny given the circulating discourses, ideologies, and professionalizing strategies used by nursing. To enable faculty to engage with and challenge these discourses and social processes, critical analysis and reflexive practices are necessary. Understanding how hierarchies between colleges and universities influence faculty work for instance, is an important starting place. As we have stated, RNs readily accepted the degree-as-entry-to-practice as a key professionalizing strategy to add status and legitimacy to the RN. This

ISSN 1925-4040 E-ISSN 1925-4059 
thinking is evident in our findings when some faculty indicated that a $\mathrm{BScN}$ degree education is superior to $\mathrm{PN}$ college diploma education. However, through the interviews, faculty could reflect and consider how each education program is suited for the practice-related responsibilities of each category of nurse. As the interviews unfolded, some faculty could see the consequences of these hierarchies and were motivated to teach differently. Reconnecting with the regulatory documents that guide RN and RPN practice helped to bring clarity to the overlap and differences between designations, ${ }^{[38]}$ and faculty mentioned how these resources could be helpful.

Siloed education, (where university and college nursing students are not taught together, even when they are co-located on the same campus), is considered problematic by most faculty. Faculty recognize that joint education could assist students to clearly articulate the key contributions they bring to patient care, and that this would support collaborative practice. Students who have experienced joint $\mathrm{PN} / \mathrm{BScN}$ education experiences have articulated these learning outcomes. ${ }^{[8]}$ Knowledge gained through joint education could extend into the workplace, providing RNs and RPNs with better collaborative skills, which have been linked to safer patient care and outcomes. ${ }^{[39]}$ Role clarity, optimizing scope of practice, and effective communication have been cited as necessary for effective collaboration. ${ }^{[34]}$ Supporting the development of these capacities during nursing education would help prepare graduates who are able to engage in collaborative care. Greater clarity could also assist faculty to teach both nursing designations to recognize expertise and promote intra-professional consultation. However, within the current framework of nursing education, systematically developing capacities for collaborative and collegial relationships remains out of reach given the lack of literature on intra-professional collaboration and evidence-informed nursing curricula. The siloed education, activation of hierarchies, and boundary work exert powerful structures that are difficult to dismantle given the lack of research and theorizing in this area ${ }^{[7]}$ Furthermore, the fact that all faculty were themselves educated in silos, and that most faculty are RNs can make it challenging to clearly comprehend and articulate the difference between nursing designations without reinforcing hierarchies.

After the credential changes were implemented in the early 2000 s, health system reform took advantage of the additional education and capabilities of both the RN and the RPN. ${ }^{[40]}$ Much of the focus, though, was on the RPNs scope of practice at that time, with few concurrent initiatives aimed at optimizing the degree preparation of the RN. Concurrent initiatives to support the expanded abilities and education of both

Published by Sciedu Press the RPN and RN with attention to changing both RPN college diploma and $\mathrm{BScN}$ university degree studies in response to credential and practice changes are lacking. It is no surprise therefore, that the RPNs and RNs have struggled with role clarity. Understanding the differences and similarities between nursing designations could assist faculty to teach intra-professional collaboration that supports effective and safe patient care and fosters professional relationships that take full advantage of the credentials of both designations of nurse within the nursing workforce. As greater understanding of the roles of the RN and RPN emerges, further opportunities to teach consultation between RPN and RN should follow. By exposing and explicating power relations and hierarchies, faculty can become more aware of the discourses that influence their teaching practice. In turn, this awareness can lead to teaching and learning strategies that dismantle power relations and hierarchies, and education that supports and strengthens intra-professional care. As nurses' scope of practice continues to evolve through legislated changes such as $\mathrm{RN}$ prescribing, strong intra-professional collaboration and understanding of role differences will continue to help every nurse optimize his or her practice.

\section{Limitations}

One limitation to this study is that it captures a group of faculty over a short period of time. A second limitation is that this study represents findings from participants who work at one school of nursing. It is possible that the findings from this sample are not generalizable to other faculty.

\section{Conclusion}

The enhanced education of both the RPN and RN has enabled a stronger intellectual base to challenge existing assumptions about patient care and nursing practice. Supporting faculty in educational reform to maximize the opportunities of this well-educated nursing workforce can assist nurses to collaborate for patient care and enhance nurses' contributions to health care outcomes. Providing education that supports role clarity and assists nurses to articulate their contributions to patient care among themselves can also be an important precursor to engaging in such dialogue with other professionals. Strengthening intra and inter-professional practice by supporting all nurses to articulate their contribution to health care is an important step for nursing. Reframing role clarity as a symptom of larger issues such as professional boundary work and hierarchies between nurses can enable faculty to address barriers to effective intra-professional collaboration, thereby promoting the contributions of all nurses.

Increasing knowledge and pedagogical strategies to support the development of intra-professional collaborative capabili- 
ties are needed. An important antecedent, though, is the need for greater faculty awareness and ability to articulate the contributions of the different designations of nurse without activating ideologies or hierarchies. Updating the patientoutcome-by-care-provider literature to reflect the changes to nursing education is also crucial to support education for effective intra-professional collaboration and the development of care delivery models that optimize the improved credentials of the RN and RPN. Many faculty in this study articulated a need for more intra-professional education to assist nursing faculty and students towards intra-professional collaborative care.

In Canada, there are over $40 \mathrm{BScN}$ programs that are colocated with PN college diploma programs. These co-located programs are ideally situated to conduct research, develop curriculum, and describe teaching practices that can support intra-professional practice. Addressing the power relations and social practices that perpetuate hierarchy will assist nursing to move forward with one voice and strengthen nurses' professional image and contributions to patient outcomes. A unified voice for nursing that recognizes difference without activating hierarchy can contribute to patient safety and a sustainable health care system. While this research focused on the Canadian context of RPNs and RNs, these two designations also exist in many other countries. As such, this research has potential for relevance beyond our Canadian borders.

\section{CONFLicts OF InTEREST Disclosure}

The authors declare that there is no conflict of interest.

\section{REFERENCES}

[1] Baker L, Egan-Lee E, Martimianakis M, et al. Relationships of power: Implications for interprofessional education. Journal of Interprofessional Care. 2011; 25: 98-104. PMid:20846045 https: //doi.org/10.3109/13561820.2010.505350

[2] Meleis A. Interprofessional education: A summary of reports and barriers to recommendations. Journal of Nursing Scholarship. 2016; 48: 106-112. https://doi.org/10.1111/jnu.12184

[3] Prentice D, Engle T, Taplay K, et al. Interprofessional collaboration: The experience of nursing and medical student interprofessional education. Global Qualitative Nursing Research. 2015; 1-9.

[4] Lim A, North N, Shaw J. Navigating professional and prescribing boundaries: Implementing nurse prescribing in New Zealand Nurse Education in Practice. 2017; 27: 1-6. PMid:28802979 https : //doi.org/10.1016/j.nepr.2017.08.009

[5] Smith D. (Ed.). Institutional ethnography as practice. Lanham: Rowman \& Littlefield Publishers Inc.; 2006.

[6] Skolnik M. Re-conceptualizing the relationship between community colleges and universities, using a conceptual framework drawn from the study of jurisdictional conflict between professions. Community College Review. 2011; 39(4): 352-375. https://doi.org/10.1 $177 / 0091552111424205$

[7] Butcher D, MacKinnon K. Educational silos in nursing: A critical review of practical nurse education in Canada. Nursing Inquiry. 2014; 22(3): 231-239. PMid:25514985

[8] Limoges J, Jagos K. Joint education fosters collaboration and role clarity between practical and degree nursing students. Journal of Nursing Education. 2016; 55(11): 623-630. PMid:27783816 https : //doi.org/10.3928/01484834-20161011-04

[9] D'Amour D, Dubois C, Déry J, et al. Measuring actual scope of nursing practice: A new tool for nurse leaders. Journal of Nursing Administration. 2012; 42(5): 248-55. PMid:22525288 https: //doi.org/10.1097/NNA.0b013e31824337f4

[10] Butcher D, MacKinnon K, Bruce A, et al. The experiences of prelicensure or pre-registration health professional students and their educators in working with intra-professional teams: A systematic review of qualitative evidence protocol. JBI Database of Systematic Reviews and Implementation Reports. 2017; 13(7): 119-130.
[11] Aiken L, Cimiotti J, Sloane D, et al. Effects of nurse staffing and nurse education on patient deaths in hospitals with different nurse work environments. MedicalCare. 2011; 49(12): 1047-1053.

[12] Kavanagh K. Mirrors: A cultural and historical interpretation of nursing pedagogies. In N. Diekelmann (Ed.), Teaching the practitioners of care: New pedagogies for the health professions. Madison: The University of Wisconsin Press; 2003. 59-153 p.

[13] McPherson K. Bedside matters: The transformation of Canadian nursing, 1900-1990. Toronto: Oxford University Press; 1996.

[14] Flexner A. Medical education in the United States and Canada. Washington, DC: Science and Health Publications, Inc.; 1910.

[15] Freidson E. Professional dominance: The social structures of medical care. New York: Atherton Press; 1970.

[16] Freidson E. Professionalism: The third logic on the practice of knowledge. Chicago: University of Chicago Press; 2001.

[17] Gidney RD, Miller WPJ. Professional gentleman: The professions in nineteenth century Ontario. Toronto: University of Toronto Pres; 1994.

[18] Gieryn TF. Boundary-work and the demarcation of science from non-science: Strains and interests in professional ideologies of scientists. American Sociological Review. 1983; 48: 781-795. https : //doi.org/10.2307/2095325

[19] Parsons T. The social system. New York: Free Press; 1951.

[20] Bevis O, Watson J. Towards a caring curriculum: A new pedagogy for nursing (Revised ed.). Sudbury, MA: Jones and Bartlett; 2000.

[21] Witz A. Patriarchy and professions: The gendered politics of occupational closure. Sociology. 1990; 24: 675-690. https ://doi.org/ 10.1177/0038038590024004007

[22] Limoges J, Jagos K. The influences of nursing education on the socialization and professional working relationships of Canadian practical and degree nursing students: A critical analysis. Nurse Education Today. 2015; 35(10): 1023-7. PMid:26260523 https : //doi.org/10.1016/j.nedt.2015.07.018

[23] Lankshear S, Rush J, Weeres A, et al. Enhancing role clarity for the Practical Nurse: A Leadership Imperative. Journal of Nursing Administration. 2016; 46(6): 300-307.

[24] Canadian Interprofessional Health Collaboration. [cited 2017 April 24]. Available from: http://www. cihc.ca 
[25] Canadian Patient Safety Institute, Canadian Framework for Teamwork and Communication. [cited 2017 April 24]. Available from: http://www . patientsafetyinstitute.ca/en/toolsResour ces/teamworkCommunication/Documents/Canadian\%20Fra mework $\% 20$ f or $\% 20$ Teamwork $\% 20$ and $\% 20$ Communications . pdf

[26] Nelson S, Tassone M, Hodges B. Creating the health care team of the future: The Toronto model for interprofessional educationand practice. Ithaca, NY: Cornell University Press; 2014.

[27] World Health Organization. Health professions network nursing and midwifery office within the department of human resources for health. Framework for action on interprofessional education and collaborative practice. 2010.

[28] Brewer B. Relationships among teams, cultural safety, and cost outcomes. Western Journal of Nursing Research. 2006; 28: 641-653. PMid:16946107 https : //doi.org/10.1177/01939459052823 03

[29] Kalish J, Lee H. The impact of teamwork on missed nursing care. Nursing Outlook. 2010; 58: 233-241. PMid:20934078 https: //doi.org/10.1016/j.outlook.2010.06.004

[30] Wheelan S, Burchill C, Tilin F. The link between teamwork and patient outcomes in intensive care units. American Journal of Critical Care. 2003; 12: 527-534. PMid:14619358

[31] Engle J, Prentice D. The ethics of interprofessional collaboration. Nursing Ethics. 2013; 20(4): 426-435. PMid:23329780 https: //doi.org/10.1177/0969733012468466

[32] Ewashen C, McInnis-Perry G, Murphy N. Interprofsesional collaboration-in-practice: The contested place of ethics. Nursing Ethics. 2013; 20(3): 325-335. PMid:23329776 https : //doi .org/ $10.1177 / 0969733012462048$
[33] Bainbridge L, Wood V. The power of prepositions: Learning with, from and about others in the context of interprofessional education. Journal of Interprofessional Care. 2012; 26: 452 458. PMid:22897364 https://doi.org/10.3109/13561820.2 012.715605

[34] Moore J, Prentice D, Taplay K. Collaboration: What does it really mean to nurses? Journal of Clinical Nursing. 2015; 24: 2052-2054. PMid:25959803 https://doi.org/10.1111/jocn.12859

[35] Orchard C. Persistent isolationist or collaborator? The nurse's role in interprofessional collaborative practice. Journal of Nursing Management. 2010; 18: 248-257. PMid:20546464 https://doi.org/10 $.1111 / j .1365-2834.2010 .01072 . x$

[36] Smith D. The Everyday World as Problematic: A Feminist Methodology. Toronto: University of Toronto Press; 1987.

[37] Smith D. Institutional ethnography: A sociology for the people. New York, NY: Rowman \& Littlefield; 2005.

[38] College of Nurses of Ontario. RN and RPN Practice: The Client, the Nurse and the Environment. [cited 2018 April 24] Available from: http://cno.org/globalassets/docs/prac/41062.pdf

[39] Liao C, Qin Y, Guo Y. The nurse-nurse collaboration behavoiur scale: Development and psychometric testing. International Journal of Nursing Sciences. 2015; 2(4): 334-339. https ://doi.org/10.1016/ j.ijnss.2015.10.005

[40] Martin D, Weeres D. Building nursing role clarity on a foundation of knowledge and knowledge application. Healthcare Management Forum. 2016; 29(3): 107-110. PMid:27060806 https : //doi.org/10.1177/0840470416633237 